\title{
Design e educação: interfaces possíveis em situações de inclusão
}

\section{Design and education: possible interfaces in inclusive situations}

\author{
SALLES, Mariana N.; Mestranda; PUC-Rio \\ marinioac@gmail.com \\ MARÇAL, Daniela; Doutora; PUC-Rio \\ dmarcal0@gmail.com \\ FARBIARZ, Jackeline; Doutora; PUC-Rio \\ jackeline@puc-rio.br
}

\section{Resumo}

Este artigo é um relato de experiência de uma sessão da oficina MÃO NA MASSA: construção de recursos inclusivos de ensino-aprendizagem, que foi realizada durante VI Simpósio Educação Especial e Inclusiva 2017 - Entre nós: Compartilhando saberes e experiências educativas pela Prefeitura de Hortolândia, no estado de São Paulo. A oficina surgiu da necessidade de formação continuada dos profissionais de educação e saúde em inclusão de crianças com deficiência. No artigo explicamos a escolha das dinâmicas, das metodologias e dos materiais. Essas escolhas foram baseadas na demanda de expansão da criação de recursos pedagógicos inclusivos. Conseguinte, descrevemos as atividades e impressões adquiridas durante a oficina. Além disso, buscamos entender: como o design pode contribuir na prática do profissional da educação e saúde para uma educação inclusiva?

Palavras Chave: educação inclusiva; recursos pedagógicos; design participativo.

\begin{abstract}
This article is a workshop experience report named Hands-on: construction of inclusive education and learning resources that was realized during the VI Simpósio Educação Especial e Inclusiva 2017 - Entre nós: Compartilhando saberes e experiências educativas organized by Hortolândia's town hall in the state of São Paulo. The workshop was idealized based on the necessity for continuous education for professionals whose work is with inclusive education. This article explains the dynamics, methodologies and materials choices. These choices were based on the increasing demand for expanding the creation of inclusive educational and learning resources. Furthermore, the activities and impressions acquired during the workshop are explained. Also, it tries to answer the question: how design can contribute to the practice of health and education professional's for an inclusive education?
\end{abstract}

Keywords: Inclusive education; pedagogical resources; partnership design. 


\section{Introdução}

Esse artigo tem como objetivo discutir uma ação do LINC (Laboratório Linguagem, Interação e Construção de Sentidos) PUC-Rio junto à profissionais de educação e saúde da rede pública da secretaria municipal de educação de Hortolândia, realizada durante o VI Simpósio Educação Especial e Inclusiva 2017 em Hortolândia, SP.

Estima-se que o município de Hortolândia tem mais de 222 mil habitantes (IBGE, 2017) e para atender a população diagnosticada com alguma deficiência, a Prefeitura vem investindo no trabalho de educação inclusiva há quase 20 anos. Hoje, conforme dados obtidos pela Prefeitura, o município possui uma infraestrutura de atendimento educacional especializado (AEE) com 21 salas de recursos multifuncionais e 30 profissionais de ensino e saúde para atender aproximadamente 500 alunos que necessitam de educação especial nas escolas regulares. Além disso, dispõe de uma escola especial com 18 profissionais, que realizam oficinas e pré-profissionalizantes e um centro de atendimento para contraturno com 8 profissionais da educação para atender aproximadamente 250 alunos.

O VI Simpósio de Educação Especial e Inclusiva teve como tema central: "Nada de nós sem nós", e foi realizado com o propósito de incentivar a partilha do conhecimento e o diálogo entre todos os que se preocupam e pesquisam no âmbito da Educação Especial e Inclusiva, como prefeituras ao redor e profissionais da educação e saúde. Nesta edição foram 691 inscritos e participantes, 10 mesas redondas e 17 minicursos.

O convite à participação do LINC (Laboratório Linguagem, Interação e Construção de Sentidos) PUC-Rio se deu no alinhamento das perspectivas de atuação e pesquisa, e com o objetivo de promover dois workshops de formação continuada junto aos profissionais de educação e saúde da rede, mediar duas mesas redondas e participar de três mesas redondas. Na perspectiva da Secretaria de Educação de Hortolândia esta ação encontra-se alinhada em seus pressupostos de que ao contribuir com a formação continuada dos profissionais da Educação Básica haverá impacto direto na qualidade do atendimento especial prestado, permeados por conhecimentos inerentes à atuação profissional e políticas públicas voltadas à Educação Especial na perspectiva inclusiva.

Na perspectiva do LINC (Laboratório de Linguagem, Interação e Construção de Sentidos) o aceite do convite deu-se em razão de o laboratório desenvolver pesquisas no campo do Design com abordagem em situações de interação - "sujeitos-objetos/sistemas/serviços-contextos". As pesquisas e ações desenvolvidas pelo LINC privilegiam o debate de questões vinculadas à educação e à interação entre as pessoas, assim como entre as pessoas, os objetos, os serviços e sistemas de informação. O referencial teórico do laboratório sustenta-se nos estudos da linguagem em Bakhtin (1997), isto é, na ideia de que é por meio da linguagem em interação que os sujeitos expressam sua relação com os objetos e sistemas de informação, ou seja, uma dimensão social dentro de uma perspectiva inclusiva dos espaços. Deste modo, o laboratório entende que os objetos só ganham forma e sentido a partir de sua relação com o usuário. 


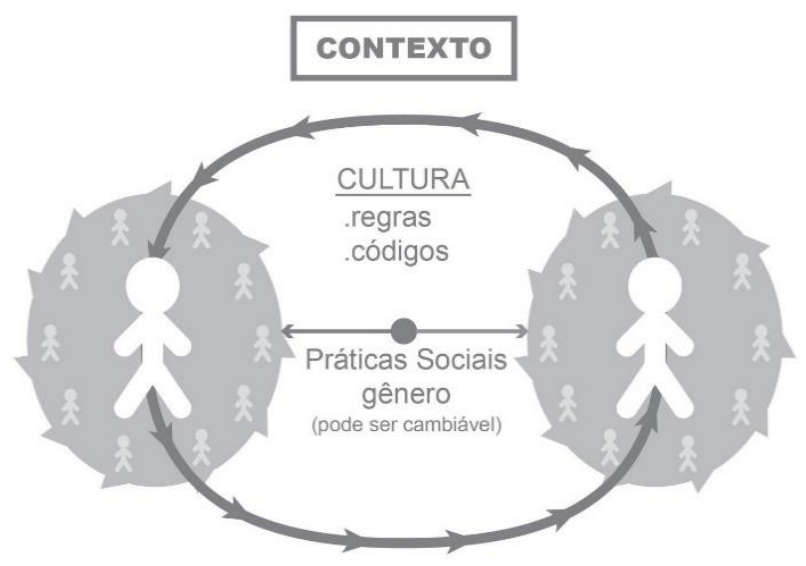

Fonte: Mariana Nioac de Salles e Jackeline Farbiarz

Neste sentido, as pesquisadoras do LINC formularam seu trabalho no Simpósio com base nos princípios do Desenho Universal para Aprendizagem e nos conceitos de design participativo.

O Desenho Universal para Aprendizagem (DUA) nos sustentou por preconizar que as práticas pedagógicas devam ser concebidas e projetadas de modo a possibilitar que alunos com capacidades diversas façam parte de um programa curricular comum, estando inseridos em ambientes em que suas singularidades possam ser atendidas, não necessitando, desse modo, de programas específicos (KING SEARS, 2009; QUAGLIA, 2015; ROSE \& MAYER, 2002).

As pesquisas do Desenho Universal para Aprendizagem (DUA) foram baseadas nas múltiplas possibilidades de configurações a partir da dimensão de três redes neurais:

Figura 2 - Redes neurais (3 dimensões)

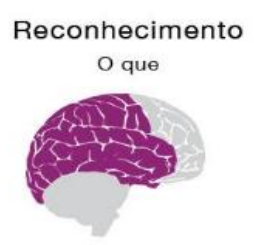

Como reunimos fatos e categorizamos o que vemos, ouvimos elemos.

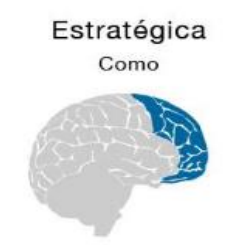

Planejamento e execução de tarefas.

Como organizamos e expressamos nossas ideias.

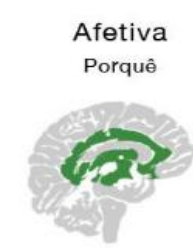

Como os alunos se envolvem

e permanecem motivados.

Como eles são desafiados,

incentivados ou interessados.

Fonte: http://www.udlcenter.org/

Esses modos são meios que cada indivíduo utiliza para interagir, aprender e processar informações. Eles podem se dar de formas diferentes e se organizam de modos singulares para cada um. Nesse sentido, o currículo e as práticas pedagógicas são projetados desde o início para suprir as necessidades do maior número de pessoas, reduzindo assim, a demanda de adaptações de materiais já existentes.

Se com o DUA projetamos para o maior numero de pessoas possível, com o design participativo buscamos compreender o singular de cada um para desenvolver em parceria com e 
para cada indivíduo. Isto é, por entender que a noção de "inclusivo" se dá em um sentido mais amplo, não mais importante, mas que leva em conta o projetar na interação, ou seja, objeto na relação, conforme na fala de Ripper e Farbiarz (2010): "a criação, o objeto de design, se constitui quando os elementos são postos juntos na ação, no meio", nesta abordagem, um design que leve em conta a singularidade do sujeito que interage. O design em parceria apresenta como característica principal que o processo com foco no ser humano seja compartilhado e partir da realidade vivida por um ou mais indivíduos (contexto); que seja vivido pelo designer, junto com o indivíduo ou um grupo e, assim deem sentido ao projetar. O produto/resultado do projetar é resultado e consequência desse processo (ARAUJO, 2017).

Além disso, o design, visto em sua dimensão transdisciplinar (BONFIM, 1997) opera junto à outras disciplinas, em parceria, e não em sobreposição a outras áreas e profissionais. Para Bonfim (1997, p.29), o Design pode ser considerado uma disciplina "transdisciplinar, pois precisaria combinar conhecimentos pertencentes a diversas áreas científicas. (...) E é possível afirmar que uma Teoria do Design não terá campo fixo de conhecimentos". Ou seja, o designer para desenvolver um sistema de informação e objetos, não basta passar pelas disciplinas, mas se moldar a elas.

Figura 3 - Teoria Transdisciplinar do Design

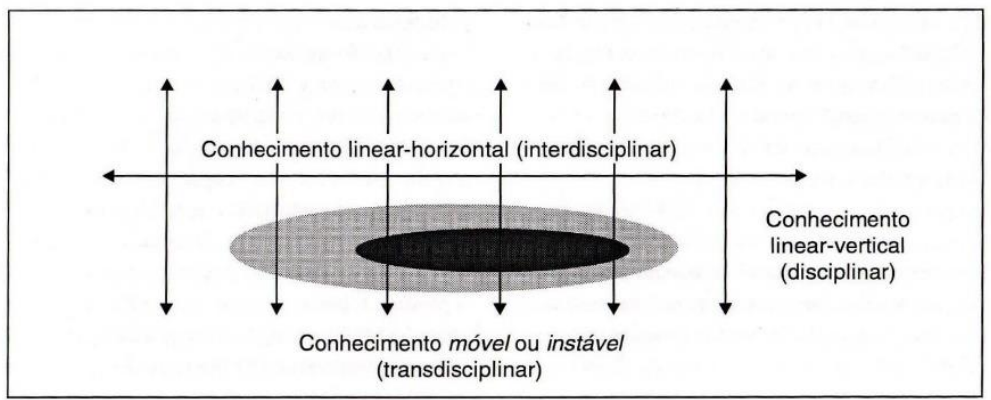

Fonte: Gustavo Bomfim (1997, p.40)

É justamente por meio da metodologia do design participativo que o design permeia as disciplinas. Pois para um designer (COUTO e RIBEIRO 2000, p.11):

\begin{abstract}
A interação entre o designer e o grupo social permite um maior entendimento do contexto real e garante a abordagem de um problema, identificado e definido pelo próprio grupo. Esta prática favorece a geração de soluções apropriadas, que estarão sempre em consonância com os anseios e necessidades da população envolvida. Permite a construção de objetos que ganharão a aceitação do grupo.
\end{abstract}

Ao assumirmos que objetos, em interação, são elementos potencializadores de novas perguntas, aproximamos o design como elemento catalisador de novas experiências e possibilidades do sujeito se constituir, de inventar a si e ao mundo. Sendo assim, pensar o projeto como relação de configurações e significações em permanente (inter)relação em lugares sociais que abarcam "o eu" e o "outro", é o caminho para estar comprometido com uma prática de projeto inclusivo.

Ao pensarmos as noções de espaços, objetos, materiais e sistemas de informações em uma dimensão inclusiva, a partir dos pressupostos de Bakhtin $(1981,2000)$, mostra-se premente pensálos como "lugar" de interação entre o eu e o outro. Se o EU é social, a relação com o meio é determinante na sua produção de discurso (BAKHTIN 1981). Portanto, reconhecemos que o meio 
(espaços, objetos, materiais e sistemas de informações) participa ativamente das atividades culturais mediada por signos que irão construir os significados nas experiências das pessoas (VYGOTSKY, 1991).

Em uma perspectiva inclusiva em que questões como aquisição de linguagem e construção de sentidos são temas centrais para as relações sociais, encontramos em Vygotsky $(1991,2000)$, Maturana $(1998,2002)$ e Kastrup $(1999 ;$ 2007) material teórico que nos sustenta no entrecruzamento de que espaços, objetos, materiais e sistemas de informações são vistos como mediadores de construção de conhecimento e de identidade. Sendo assim, partimos do entendimento de que, enquanto lugar de construção de afeto e relação, o meio participa de processos cognitivos ao viabilizar uma transformação estrutural no conviver (MATURANA, 2002) e se apresenta como espaços favoráveis a novos modos de ser, que permitem a invenção de si e do mundo (KASTRUP, 2007).

Como metodologia de análise para discutirmos os dados encontrados nas falas das professoras durante a discussão inicial, escolhemos dois elementos da sociolinguística interacional (TANNEN e WALLAT, 1986), as noções de enquadre, em que os participantes de uma situação de comunicação face a face deveriam estar atentos aos sinais que contextualizam os enquadres, para assim perceberem as mudanças de situações, já que "o enquadre contém um conjunto de instruções para que a/o ouvinte possa entender uma dada mensagem" (BATESTON, 1972, p. 85); e, também, alinhamento, em que as pistas compreendidas pelos interlocutores durante os enunciados (contextualização) suscitam alinhamentos por parte destes e podem ser linguísticas, paralinguísticas, prosódicas e não verbais (GUMPERZ, 1982).

Para discussão dos resultados do workshop, analisaremos os resultados a partir do que foi observado pelas pesquisadoras partindo do referencial teórico apresentado na introdução do presente artigo.

Diante do exposto entendemos que esta parceria e o convite para o workshop, se deram em função do entendimento ampliado com relação ao campo da educação em interface com o design. Dado que entendemos as práticas enquanto processo e que o diálogo e a troca entre as áreas contribui para educação inclusiva por pensar a prática a partir do problematizar ações, da observação do contexto e, por fim, a construção coletiva do fazer, ou seja, fazer com e não fazer para.

\section{Desenhando a ação - Workshop}

A partir do que já foi apresentado como fundamentação e pressupostos, de experiências anteriores de oficinas com profissionais da educação e saúde em outros eventos e de demandas da organização do evento de criação de recursos de ensino-aprendizagem inclusivos, que explorassem a multisensorialidade das crianças com deficiência, criamos um workshop com o titulo "MÃO NA MASSA: construção de recursos inclusivos de ensino-aprendizagem".

O objetivo da oficina foi sensibilizar os participantes (educadores, gestores e afins) com a apresentação de metodologias, conceitos e técnicas que permitem enxergar por meio do observar, do projetar e do fazer em conjunto, sistemas e/ou objetos de mediação de ensino-aprendizagem que sustentam práticas inclusivas.

À vista disso, apresentamos estas metodologias para o grupo: 
1. Desenho Universal para Aprendizagem (DUA)

- Proporcionar múltiplos meios de envolvimento;

- Proporcionar múltiplos meios de representação;

- Proporcionar múltiplos meios de ação e expressão.

2. Metodologia do Design Participativo

- observação do cenário;

- contextualização;

- interações entre os sujeitos;

- problematização, potências nos espaço e dos sujeitos e oportunidades.

Também apresentamos para o grupo, um quadro conceitual dos principais sistemas sensoriais envolvidos nos processos de aprendizagem, visto que há a demanda de ampliação de repertório sobre as questões relativas à percepção e interação sensorial com o meio, de crianças com deficiências e dificuldades de aprendizagem.

Figura 4 - Quadro conceitual dos principais sistemas sensoriais envolvidos nos processos de aprendizagem

\begin{tabular}{|c|l|}
\hline VISUAL & $\begin{array}{l}\text { As ideias, conceitos e informações são processadas e } \\
\text { associadas através de imagens e modelos visuais. }\end{array}$ \\
\hline AUDITIVO & $\begin{array}{l}\text { As ideias, conceitos e informações são processadas e } \\
\text { associadas através da audição como fala, música, ritmos... }\end{array}$ \\
\hline TÁTIL & $\begin{array}{l}\text { As ideias, conceitos e informações são processadas e } \\
\text { associadas através de toques e manipulação de objetos. }\end{array}$ \\
\hline CINESTÉSICO & $\begin{array}{l}\text { As ideias, conceitos e informações são processadas e } \\
\text { associadas através de atividades corporais/espaciais. }\end{array}$ \\
\hline
\end{tabular}

Fonte: Quadro criado pela pesquisadora Daniela Marçal

Dessa maneira, como estratégia para contribuir na percepção e na interação do aluno por meio dos sentidos, introduzimos durante a parte prática do workshop, técnicas de implementação de respostas luminosas, auditivas e/ou táteis (vibração e textura) aos recursos didáticos propostos pelos participantes das oficinas. $\mathrm{O}$ uso de recursos multissensoriais possibilita atingir diversos dos modos de apreender os conteúdos e, desta forma, desenvolver recursos mais adequados às potências de cada aluno.

Assim, o workshop foi desenhado do seguinte modo:

1. Introdução dos principais conceitos do Desenho Universal para Aprendizagem e da metodologia do design participativo;

2. Exercício de sensibilização através da "leitura de imagem";

3. Discussão do grupo sobre a atividade da "leitura de imagem";

4. Apresentação do material de trabalho da oficina e uma pequena introdução sobre circuito básico e seu uso para atividades sensoriais com crianças com deficiências;

5. Oficina de construção de recursos inclusivos com uso de baixa tecnologia (mão na massa).

\section{Relato do Workshop}

Ao chegamos ao Simpósio percorrendo os espaços do evento, percebemos, através das fotos expostas nos corredores sob forma de relato das atividades realizadas pelas escolas em sala de aula, 
que os profissionais presentes tinham experiência no desenvolvimento de recursos para crianças com deficiência. As fotos descreviam, por meio de imagens, narrativas de uma prática que abarcava objetos, materiais e sistemas de informação como forma de mediação.

Assim sendo, nos questionamos até que ponto os conceitos, as informações e as experiências que estávamos partilhando como grupo serviria de adensamento para práticas de ensino-aprendizagem reflexivas? Nosso material seria utilizado para que os profissionais pudessem potencializar as habilidades dos seus alunos como aumento de repertório das práticas de sala já utilizada pelas professoras? Resumindo, durante as atividades mantivemos a pergunta em mente: Como o design pode contribuir para práticas que tenham como premissa uma educação inclusiva?

Foram dois dias de oficina, na primeira oficina tinham quinze participantes e na segunda tinham trinta e cinco participantes. Tomamos como recorte para o presente artigo o segundo dia de oficina.

A oficina teve início com os organizadores do evento apresentando as pesquisadoras e suas áreas de atuação e pesquisa. Logo após a apresentação, iniciamos às atividades introduzindo os princípios do DUA e as etapas do design em parceria, com apresentação no powerpoint. Além da apresentação, distribuímos folhas com um pequeno quadro sob forma de auxílio de conteúdo (anexo).

Após a apresentação dos princípios do DUA e da metodologia do design participativo, abrimos para perguntas e, em seguida, iniciamos a atividade de sensibilização. Nesta atividade, propomos a divisão em grupos de três a quatro pessoas. Distribuímos para os grupo fichas "A" e "B", nas imagens os textos eram em holandês, portanto, não era possível para o grupo fazer a tradução. Metade dos grupos recebeu a ficha A e a outra metade ficha B, com as diferentes imagens:

Figura 5 - Ficha A utilizada em dinâmica para trabalhar interpretação de linguagem

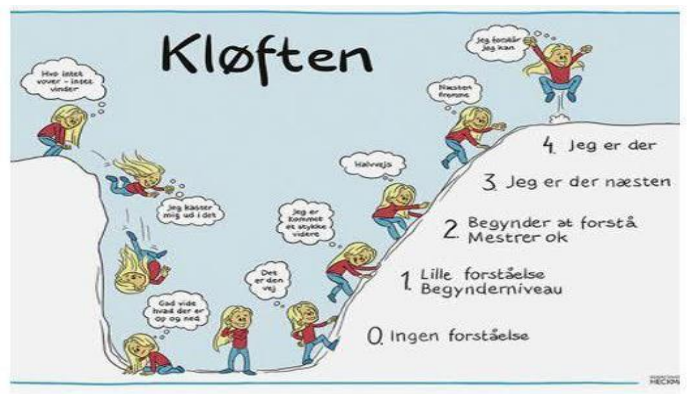

Fonte: http://www.kompetencehusetheckmann.dk/produkt/kloeften-a1-plakat/

Figura 6 - Ficha B utilizada em dinâmica para trabalhar interpretação de linguagem

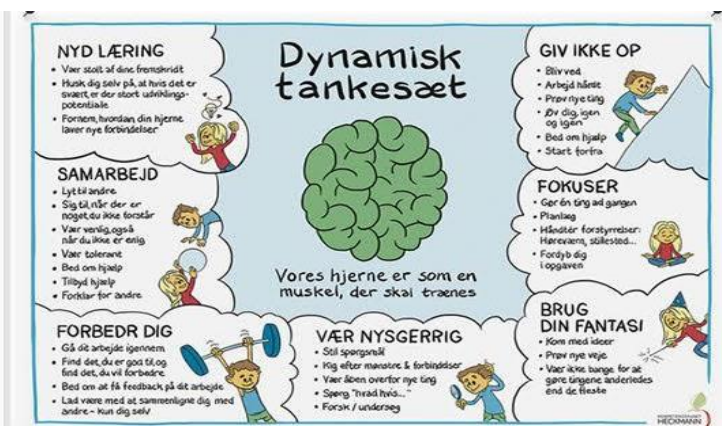


Fonte: http://www.kompetencehusetheckmann.dk/produkt/dynamisk-tankesaet-a1-plakat/

O objetivo da dinâmica era o grupo "ler" (SANT'ANNA, 1999) e interpretar as imagens de modo que pudessem depois de discutirem em seus grupos, apresentar para o restante da turma a narrativa construída e como se deu esse processo, ou seja, quais elementos participaram da elaboração.

Demos 10 minutos para a atividade nos pequenos grupos e depois abrimos para as apresentações e discussão do grupão.

Enquanto cada grupo apresentava sua narrativa e seus processos de leitura das imagens, escrevemos no quadro as palavras que foram usadas pelas participantes para descrever as cenas (narrativas). Assim o grupo poderia visualizar o conjunto de palavras e significados construídos coletivamente. A exposição das palavras fez como cada grupo dialogasse o que "leu", interpretou, a partir das imagens. Dessa forma, os participantes da oficina perceberam como cada um processa a informação de maneiras diferente.

Figura 7 - Quadro com as palavras faladas por cada grupo para descrever as imagens

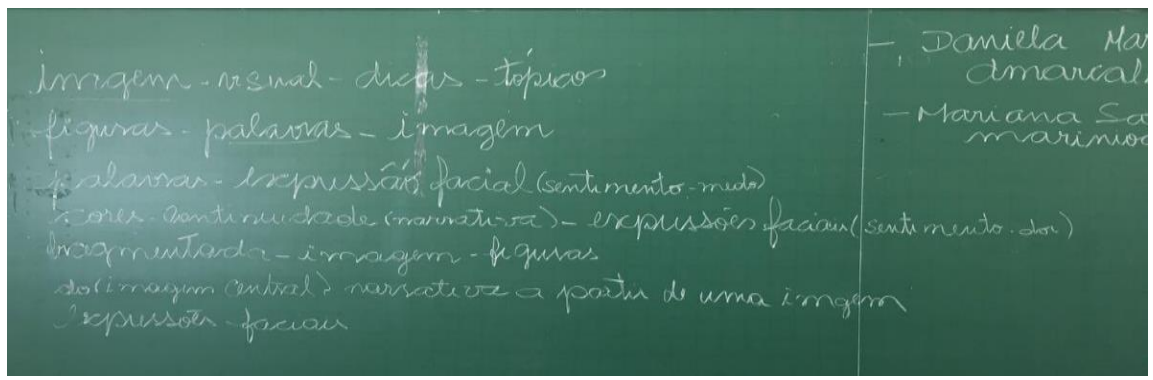

Fonte: Mariana Nioac de Salles

Durante as apresentações os participantes relataram que tiveram que procurar estratégias para decodificar as cenas, já que não entendiam o que estava escrito. Foi relatado que usaram como estratégias, em sua maioria, pistas visuais como: expressões faciais; palavras semelhanças linguísticas com o português e inglês; e, detalhes em relação aos contextos das narrativas.

Após a dinâmica de sensibilização e do debate, partimos para a atividade prática: "mão na massa". Primeiro apresentamos o objetivo da atividade: prototiparmos recursos pedagógicos multissensoriais que atendessem à demandas reais trazidas pelos participantes baseados em suas experiências do dia a dia com os alunos.

Em seguida, apresentamos o material disponibilizado, que baseado no contexto escolar, escolhemos materiais comuns ao ambiente de ensino-aprendizagem e como forma de ampliar as respostas dos objetos de interação, apresentamos técnicas acessíveis, de baixo custo e de baixa tecnologia, para que os profissionais da educação pudessem expandir as suas possibilidades de criação de recursos multissensoriais. Os materiais escolhidos foram: cartolina, papel enrugado, papelão, cola, tesoura, pilot, papel colorido, papel alumínio, fitas coloridas, LED's e baterias 3v.

Antes de dar início às atividades, apresentamos como se faz um circuito de energia básico com apenas um LED, uma bateria de $3 \mathrm{v}$ e papel alumínio. Para isso usamos como referência o modelo abaixo, que foi distribuído para todos os participantes. 
Figura 8 - Circuito básico

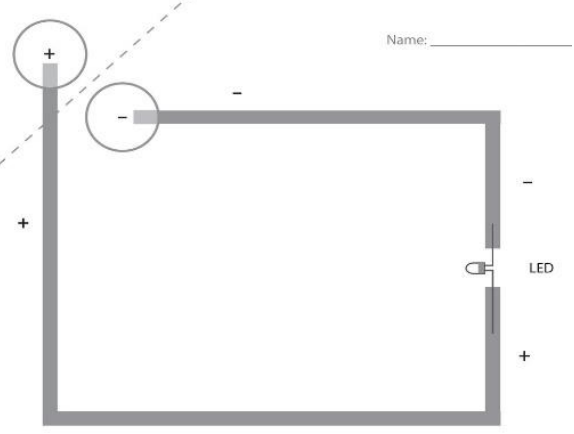

Fonte: Elaborando

Os participantes, então, retornaram aos grupos iniciais e entre eles escolheram o que iriam fazer, baseados em suas experiências de sala de aula, nos seus contextos e nas demandas escolares experimentadas por elas: ano escolar em que atuam e casos vivenciados em sala de aula. Nesse momento as pesquisadoras funcionaram como apoio para dúvidas e ajudar em alguma ação em que elas não sentiam-se à vontade ou apresentassem dificuldade. O foco da atividade prática não estava na qualidade do protótipo, mas sim na percepção, por parte dos participantes, de seus processos projetuais participativos, assim, a aplicabilidade e nas dimensões sensoriais dos recursos de acordo com suas vivências. A atividade durou uma hora e meia desde a concepção até a fabricação dos protótipos funcionais (recurso).

Figura 9 - Sala de aula regular dividida em grupos durante a realização da oficina

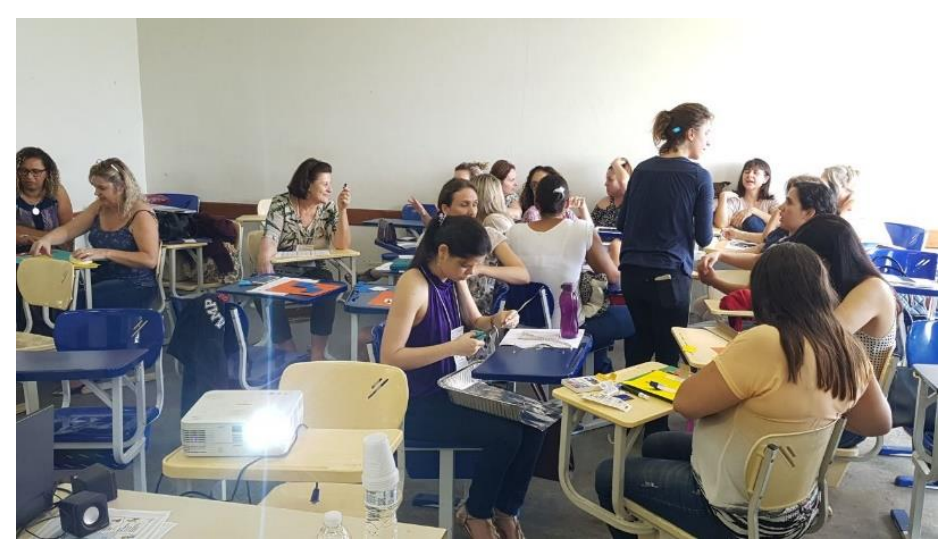

Fonte: Daniela Marçal

Os recursos apresentados, apesar de terem temáticas semelhantes, eram diversos em suas possibilidades de interação e construção. Um grupo fez um sinal de trânsito para ensinar as cores e regras de trânsito para crianças com autismo. Outro grupo fez uma segmento de números no qual o aluno teria que encaixar as peças em sequência correta para, sob forma de resposta sensorial, acender as luzes do recurso. Um outro, fez um exemplo de adição matemática, que acendia a luz quando o aluno posicionava o número correto. E outro fez um circuito de carros baseado em cores para praticar reação motora e ensinar cores, em que para acender a luz o aluno tinha que posicionar o carro na garagem da cor que o professor pedia: 
Figura 10 - Recurso multissensorial de sequência de números desenvolvido com baixa tecnologia

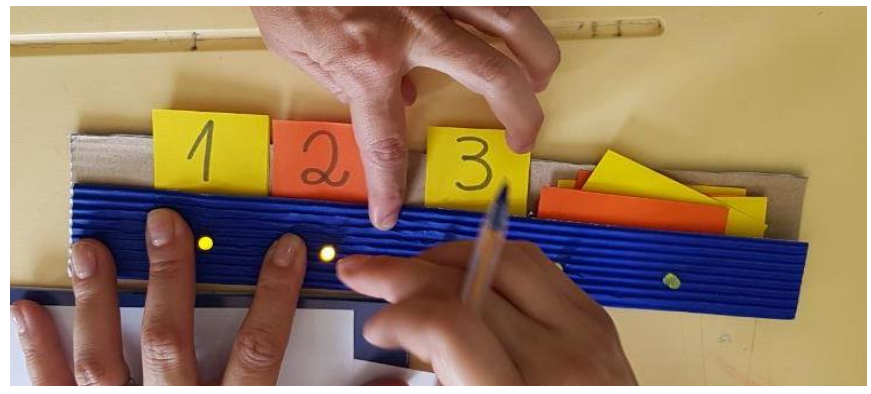

Fonte: Daniela Marçal

Figura 11 - Recurso multissensorial de sequência de números desenvolvido com baixa tecnologia

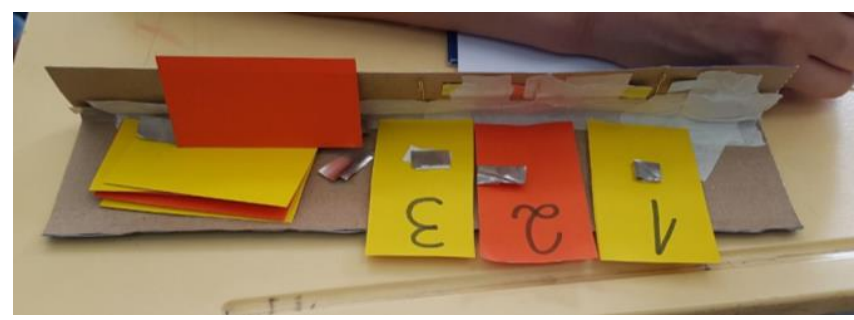

Fonte: Daniela Marçal

Figura 12 - Recurso multissensorial de adição de números desenvolvido com baixa tecnologia

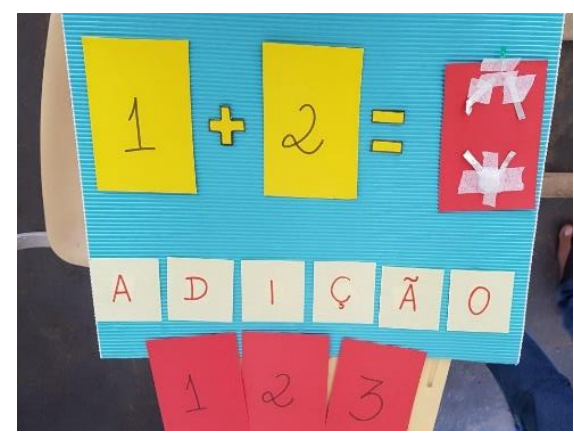

Fonte: Daniela Marçal

Figura 13 - Recurso multissensorial de sinal de trânsito para aprendizagem regras do transito e cores

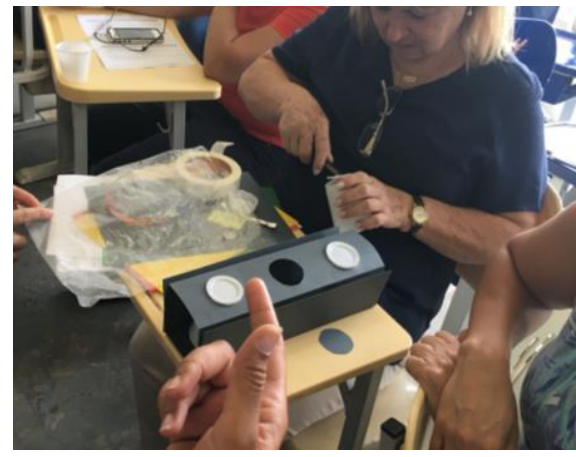


Fonte: Daniela Marçal

Figura 14 - Recurso multissensorial de circuito de carro para aprendizagem de cores e reação motora

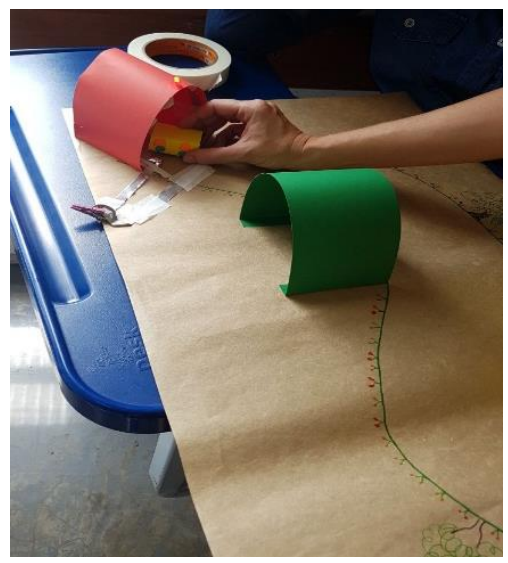

Fonte: Daniela Marçal

Após as apresentações de cada recurso, encerramos as atividades e recolhemos, por meio de registros fotográficos e anotações, material suficiente para uma análise da ação realizada.

\section{Apresentação dos resultados}

Os dados foram analisados a partir de duas etapas do workshop. A etapa de sensibilização, que envolveu leitura de imagem, e a etapa mão na massa, em que os participantes em grupo desenvolveram recursos com princípios inclusivos para crianças com deficiência.

\subsection{Análise da discussão do grupo sobre a atividade da "leitura de imagem"}

Primeiro fizemos um levantamento das palavras mais usadas pelas professoras ao falar sobre quais estratégias e pistas usaram, a partir de suas práticas, para analisar as imagens apresentadas, imagens A e B, são elas: imagem; visual; dicas; tópicos; figuras; palavras; expressão facial; cores; fragmentado.

Análise à luz da Sociolinguística Interacional nos indicou os seguintes elementos: 1) Enquadre - professoras em interação com imagens; e, 2) Alinhamento - a) pistas visuais; b) pistas linguísticas; c) pistas faciais.

a) pistas visuais - a partir de pistas visuais (cor, fragmentos e tópicos) que puderam contextualizar as cenas e assim, construir uma narrativa;

b) pistas linguísticas - palavras que apesar de escritas em dinamarquês possuem grafia (visual) ou sonoridade (verbal) semelhante ao português;

c) pistas faciais - expressões faciais (visual e subjetivas) que ajudaram a entender o sentimento dos personagens.

Ao final do debate houve consenso de que as pistas verbo/visuais foram as pistas que mais auxiliaram aos grupos a compreender e construir as narrativas. Ficou evidente, também, que apesar de as narrativas apresentarem contextos semelhantes, algumas singularidades se deram em função das diferentes percepções de detalhes e/ou elementos da ordem do design percebidos por uns grupos e por outros não. Tal compreensão nos demonstra a importância dos princípios do design como harmonia, equilíbrio, hierarquia, proporção, contraste e etc, são escolhas de projetos por 
parte dos designers, que fazem parte da percepção e compreensão dos sujeitos diante da interação com as imagens. Cada grupo percebeu e apreendeu a cena por diferentes singularidades.

Nesta perspectiva, podemos apontar para importância de práticas projetuais que a partir da observação e da compreensão do contexto permitam abarcar as singularidades e potências de cada um, para a partir delas, o conhecimento poder ser entendido pelo maior número de pessoas. $\mathrm{O}$ designer no lugar de co-autor das construções de sentidos em espaços inclusivos, ao ter consciência de suas escolhas projetuais possibilita que sujeitos possam se apropriar de pistas que o auxiliem no processo de desenvolvimento de suas potências e habilidades.

\subsection{Análise dos recursos pedagógicos desenvolvidos pelas professoras}

Como já observado anteriormente as educadoras possuíam bagagem de formação e experiência com a criação e desenvolvimento de recursos para crianças com deficiência.

Pudemos observar, também, que todos os projetos apresentados partiram de necessidades de seus contextos escolares (contextualização) e se apropriaram dos conceitos de multissensorialidade, pois foram usados materiais de texturas diversas e, também, o uso dos circuitos eletrônicos básicos como forma de inputs e outputs de informação.

Outro dado que nos chamou atenção, foi o fato dos grupos, ao falarem sobre suas experiências de sala e seus projetos, expressarem que princípios dos DUA como múltiplas formas de ação e interação (uso de linguagens diferentes) foram pensados no âmbito do processo de construção dos recursos.

Apesar de trabalharmos com um cenário hipotético, pois, devido a restrição de tempo, pulamos a etapa de observação do cenário e a contextualização foi dada a partir da experiência vivida pelos participantes. Mesmo assim, as propostas dos projetos foram originadas de situações da prática do dia a dia, dos ambientes de ensino-aprendizagem e dos participantes. Então, pudemos verificar, em seus relatos e protótipos, que observaram e destacaram as singularidades dos seus sujeitos/usuários (os sujeitos das prática de sala de aula).

Portanto, apontamos que metodologias como a do design em parceria, em situações de formação continuada para profissionais da educação e saúde, pode mostrar-se como uma importante apropriação para que recursos criados sejam desenvolvidos sob a demanda das individualidades de cada aluno, deste modo, funcionando como ferramenta para que as potência e dificuldades destes sujeitos sejam parâmetros de projetos que tem como premissa serem inclusivos.

\section{Conclusão}

A atuação no simpósio realizado pela Prefeitura de Hortolândia, que reuniu profissionais da educação, grande maioria e, também, da saúde, nos trouxe alguns apontamentos e reflexões. Apesar da oficina ter sido realizada pelas pesquisadoras em outros eventos, em nenhuma outra edição observamos a criação e desenvolvimento de recursos de forma diligente e com nível de elaboração acima do esperado. Tal observação se mostrou relevante, visto que, a secretaria de educação de Hortolândia investe na formação contínua desses profissionais.

A experiência dos participantes no desenvolvimento de recursos inclusivos, ao invés de se mostrar um impeditivo de apreender novas conceitos, nos mostrou que a apresentação dos conteúdos do Desenho Universal para Aprendizagem (DUA) e da metodologia do design 
participativo, operou como ampliação de repertório para que os participantes pudessem compreender um cenário complexo em que o escopo se dá particularmente na contextualização e singularização do "projetar com" e, também, no entendimento da dimensão sensorial que atravessa os sujeitos com deficiência.

A partir dos relatos durante a atividade de sensibilização, percebemos que a oficina ofereceu aos participantes a oportunidade de refletir sobre a ampliação das múltiplas percepções de práticas na educação e dos diferentes modos de interação. Tal análise se deu em função de os participantes perceberem-se deslocados de lugar, encontraram-se no lugar do aluno em situação de inclusão. Seus relatos evidenciaram que o fato de não possuírem habilidades com o dinamarquês, tiveram que recorrer a estratégias não habituais em suas atividades cotidianas, como por exemplo interpretação da imagem por meio de pistas visuais, estabelecer relação imagem, texto e contexto, e ainda, procurar em suas vivências repertórios prévios que os ajudasse na decodificação de narrativas singulares.

Sendo assim, acreditamos que os participantes puderam experimentar, vivenciar e verificar a relevância do entendimento de que materiais de ensino-aprendizagem multissensoriais, desenvolvidos a partir das habilidades e do contexto dos alunos em situação de inclusão, dão a eles a oportunidade de desenvolver suas competências e aprender no âmbito da sua potência e não de sua deficiência.

Apesar da percepção de que o resultado foi positivo, na avaliação das pesquisadoras, ao responder à pergunta: como o design pode contribuir para práticas que tenham como premissa uma educação inclusiva? Ficou evidente a importância da construção espaços em que os sujeitos da cena educacional percebam o design como espaço de interface entre saberes. Os educadores através da expertise de suas práticas de ensino-aprendizagem ao se apropriarem de metodologias de análise de cenário, design em parcerias e processos projetuais de objetos e sistemas de informação que visem diminuir barreiras nos processos de ensino-aprendizagem, podem ampliar seus repertórios e desenvolver junto aos alunos, com e sem deficiência, uma prática que seja mais inclusiva e reflexiva no âmbito dos diferentes modos de interação e apreensão de conteúdos e informações construídas em sala de aula.

Os dados evidenciam, primeiramente, a pertinência da ampliação da discussão sobre os agentes e as estruturas envolvidas em processos inclusivos, acreditamos a relevância de envolver os alunos, o ambiente físico (arquitetura, objeto e layout), as dinâmicas de sala de aula, a escola e as relações entre os atores deste cenário nos caminhos propostos.

Segundamente, apontamos para a necessidade da aproximação dos saberes das duas áreas, educação e design sob forma de ampliação na construção de ferramentas, estratégias e metodologias que deem conta da complexidade que o assunto crianças com deficiência em situação de inclusão demanda.

Acreditamos, deste modo, que experiências como a do Simpósio de Hortolândia nos auxilie a encontrar caminhos que possam contribuir para que educadores e alunos trabalhar os conteúdos escolares a partir de suas potências, suas singularidades, respeitando o tempo de cada um e, principalmente, construindo uma cultura escolar inclusiva.

\section{Referências}


ARAUJO, Renata Mattos Eyer de; "Um olhar sobre o design social e a prática do design em parceria", p. 19-28.In: Ecovisões projetuais: pesquisas em design e sustentabilidade no Brasil. São Paulo: Blucher, 2017.

BATESTON, G. (1972). A theory of play and fantasy. In Steps to an ecology of mind (pp. 177-193). Cambridge: Cambridge University Press

BAKHTIN, M., Estética da criação verbal. São Paulo: Martins Fontes, 2007.

Marxismo e Filosofia da Linguagem (1929). Tradução de Michel Lahud e Yara F. Vieira. São Paulo: Editora Hucitec, 1986.

Problemas da poética de Dostoiévski. Trad. Paulo Bezerra. Rio de Janeiro: Forense Universitária, 2005.

. $O$ autor e a personagem na atividade estética. In: Estética da criação verbal. Trad.

Paulo Bezerra. São Paulo: Martins Fontes, 2003.

. O problema do texto na lingüística, na filologia e em outras ciências humanas. In:

Estética da criação verbal. Trad. Paulo Bezerra. São Paulo: Martins Fontes, 2003.

. O discurso no romance. Trad. Aurora F. Bernardini et al. In:

. Questões de literatura e estética. São Paulo: Hucitec, 1990.

BOMFIM, G. A. Fundamentos de uma Teoria Transdisciplinar do Design: morfologia dos objetos de uso e sistemas de comunicação. Estudos em Design. v. 5, n. 2. Rio de Janeiro: aend-br, 1997. p. 27-41

CAST . Universal Design for Learning Guidelines version 2.0. Wakefield, MA: Author, 2011.

COUTO, R. M. S.; RIBEIRO, F. N. F. Ensino de Disciplinas de Projeto em Curso de Design sob o Enfoque do Design em Parceria. Rio de Janeiro: PUC-Rio, 2000

FARBIARZ, J. L.; RIPPER, J. L. M. Instantâneos de interações. Rio de Janeiro: PUC-Rio, 2010.

INSTITUTO BRASILEIRO DE GEOGRAFIA E ESTATÍSTICA (IBGE). Estimativa Populacional 2017. Dispoível em: https://cidades.ibge.gov.br/brasil/sp/hortolandia/panorama . Acesso em: $02 / 04 / 2018$

SANT'ANNA, Affonso Romano de. Ler o mundo. Tudo é texto. Não é só quem lê um livro que lê. In: O Globo, 8 nov. 1999

L. A. L., Design Método. Rio de Janeiro: Editora Puc-Rio/ Editora Novas Ideias, 2006. 
KASTRUP, V. A invenção de si e do mundo. Campinas-São Paulo: Papirus, 1999.

A invenção de si e do mundo: uma introdução do tempo e do coletivo no estudo da cognição. Belo Horizonte: Autêntica, 2007a. 256 p.

KING-SEARS, Margaret. "Universal Design for Learning: Technology and Pedagogy." Learning Disability Quarterly, vol. 32, no. 4, 2009, pp. 199-201. JSTOR, JSTOR, www.jstor.org/stable/27740372.

MATURANA, H. Cognição, ciência e vida cotidiana. Belo Horizonte: Editora da UFMG, 2002. 200 p . Emoções e linguagem na educação e na política. Belo Horizonte: UFMG,

1998.

. Da biologia à psicologia. Porto Alegre: Artes Médicas, 1998.

. H.; REZEPEKA, N. S. Formação humana e capacitação. Petrópolis: Vozes, 2002.

TANNEN.\& WALLAT, Cynthia. Interative frames and knowledge schemas in interation. In: TANNEN, Deborah (ed) Framing discourse. New York: Oxford University Press, 1986.

VYGOTSKY, Lev Semenovich. A Construção do pensamento e da Linguagem. São Paulo: Martins Fontes, 2000.

Pensamento e linguagem. São Paulo: Martins Fontes, 1991. 